\title{
Substitution of Serine for Non-disulphide-bond-forming Cysteine in Grass Carp (Ctenopharygodon Idellus) Growth Hormone Improves In Vitro Oxidative Renaturation
}

\author{
Michael Yiu-Kwong Leung and Walter Kwok-Keung Ho* \\ Department of Biochemistry, The Chinese University of Hong Kong, Shatin, Hong Kong Special Administrative Region
}

Received 12 October 2005, Accepted 2 December

\begin{abstract}
Native grass carp (Ctenopharygodon idellus) growth hormone, has 5 cysteine amino acid residues, forms two disulphide bridges in its mature form. Recombinant grass carp growth hormone, when over-expressed in $E$. coli, forms inclusion bodies. In vitro oxidative renaturation of guanidinehydrochloride dissolved recombinant grass carp growth hormone was achieved by sequential dilution and stepwise dialysis at $\mathrm{pH}$ 8.5. The redox potential of the refolding cocktail was maintained by glutathione disulphide/glutathione couple. The oxidative refolded protein is heterogeneous, and contains multimers, oligomers and monomers. The presence of non-disulphide-bond-forming cysteine in recombinant grass carp growth hormone enhances intermolecular disulphide bond formation and also nonnative intramolecular disulphide bond formation during protein folding. The non-disulphide-bond-forming cysteine was converted to serine by PCR-mediated site-directed mutagenesis. The resulting 4-cysteine grass carp growth hormone has improved in vitro oxidative refolding properties when studied by gel filtration and reverse phase chromatography. The refolded 4-cysteine form has less hydrophobic aggregate and has only one monomeric isoform. Both refolded 4-cysteine and 5-cystiene forms are active in radioreceptor binding assay.
\end{abstract}

Keywords: Ctenopharygodon idellus, Cysteine, Disulphide bond, Grass carp growth hormone, In vitro protein refolding

\section{Introduction}

The protein architecture and the protein folding mechanism of eukaryote are more advanced than the prokaryotic counterpart.

*To whom correspondence should be addressed.

Tel: 852-2609-6345; Fax: 852-2603-5123

E-mail: walterk@cuhk.edu.hk
The proper folding of disulphide-bond-forming protein in eukaryote requires proper redox potential, molecular chaperone (Jakob et al., 1994; Hartl 1996), Ero 1p (ER oxidation 1) (Frand et al., 1998; Frand et al., 2000) and protein disulphide isomerase (PDI) (Creighton et al., 1980; Bulled et al., 1988; Weissman et al., 1993). Eukaryotic protein when overexpressed in heterologous system such as E. coli usually forms inclusion bodies (Williams et al., 1982; Hartley et al., 1988; Puri et al., 1992). Prokaryote, which has more reducing cytoplasm, has no proper molecular chaperone for heterologous protein, and has no PDI in cytoplasm (Jonda et al., 1999), does not favor the proper folding of eukaryotic protein. In fact, newly synthesized eukaryotic protein in E. coli usually folds improperly and has exposed hydrophobic regions. In hydrophilic cytoplasm, the exposed hydrophobic regions tend to aggregate and result in the formation of inclusion bodies in order to minimize free energy.

Recombinant protein, which forms inclusion bodies in prokaryote, requires in vitro refolding to be biologically active, and disulphide-bond-forming protein requires oxidative refolding. A popular method to refold protein expressed as inclusion bodies, is to dissolve inclusion bodies in denaturant like urea or guanidine hydrochloride $(\mathrm{GdnHCl})$ and the gradual removal of denaturant by dialysis facilitates proteinrefolding process (West et al., 1998). Alternate method is on column refolding, which is achieved by the removal of denaturant by chromatographic methods (Li et al., 2004). Protein folding under such conditions is solely driven by free energy. The gradual dilution/removal of denaturant initiated unfolded protein to collapse to form compact intermediate state/molten globule with native-like secondary structure (Dolgikh et al., 1981; Ohgushi et al., 1983; Dolgikh et al., 1984; Dolgikh et al., 1985). The secondary structures of molten globule are orientated in native tertiary positions. Molten globule equilibrates with protein aggregate, nonnative topology protein and native topology protein. The resulting refolded product is thus a mixture of protein with different topologies, and hydrophobic aggregate. The hydrophobic 
aggregation and non-native topology folding compete with the native topology folding. The formation of molten globule is fast and is in millisecond scale (Eaton et al., 1997), and the rate-limiting step is the transition from molten globule to native topology, which progresses in seconds (Sosnick et al., 1996). The incorporation of additives such as cationic amino acid (Rudolph et al., 1996; Lilie et al., 1998; De Bernande et al., 1999), polymers (Nath et al., 2001), detergent (Nath et al., 2001), and the proper manipulation of parameters like hydrostatic pressure (Gorovits et al., 1998), $\mathrm{pH}$ (Rudolph et al., 1996; Bhuyan et al., 2001), temperature (Rudolph et al., 1996), redox potential (Yin et al., 2004), ionic strength (Rudolph et al., 1996; Futami et al., 2000; Tayyab et al., 2002), and protein concentration (Bhuyan et al., 2001; Huth et al., 1994) can push the equilibrium towards native topology folding. The presence of non-disulphide-bond-forming cysteine in disulphide-bond-forming protein will further increase the portion of improper folded protein in the in vitro refolded product. In the absence of PDI, the formation of disulphide bond is governed by random collision of cysteine amino acid residues of the polypeptide. Under these circumstances, the formation of non-native intramolecular disulphide bonds and intermolecular disulphide bonds becomes possible.

Growth hormone or somatomedin is a polypeptide hormone and its principle function is somatogenic action. Grass carp growth hormone (gcGH) has 188 amino acids in the mature form. There are five cysteine (Cys) amino acid residues in gcGH, which are located at amino acid position 49, 123, 161, 178 and 186 respectively (Ho et al., 1989). In native mature gcGH, Cys 49 bonds with Cys 161 and Cys 178 bonds with Cys 186 to form two disulphide bridges. Cys 123 is a nondisulphide-bond-forming Cys. The non-disulphide-bond-forming cysteine of gcGH was converted to serine by PCR-mediated site-directed mutagenesis and leading to a 4-Cys rgcGH. The study of in vitro refolded product of 4-Cys and 5-Cys recombinant grass carp growth hormone (rgcGH) suggests 4Cys rgcGH has better refolding properties and yield a more homogeneous refolding mixture than 5-Cys $\mathrm{rgcGH}$. Both refolded 4-Cys and 5-Cys rgcGH share similar potency with ngcGH in receptor binding assay. The improvement of the folding procedures of $\mathrm{rgcGH}$ may finally lead to the application of $\mathrm{rgcGH}$ in fish farming.

\section{Materials and Methods}

Site-directed mutagenesis. Double PCR method was used to generate substitution of serine for cysteine at amino acid position 123 of mature gcGH. In the first PCR, forward primer (5'TACGAC TCACTATAGGG3') and reverse primer (5'TGGTTGACCATCCA GAGATCCCTTGAT3') of each $0.5 \mu \mathrm{g}$ were added together with template plasmid (pADH5C) of $20 \mathrm{ng}$ to PCR cocktail of $100 \mu \mathrm{l}$ final volume. The PCR cocktail contains $200 \mu \mathrm{M}$ of dNTP mix (Amersham Biosciences) and 10 units of $P f u$ DNA polymerase (Stratagene). The underlined nucleotide is the introduced mutation. A 30 cycle PCR profile of denaturation at $96^{\circ} \mathrm{C}$ for $2 \mathrm{~min}$, annealing at $55^{\circ} \mathrm{C}$ for $2 \mathrm{~min}$ and extension at $72^{\circ} \mathrm{C}$ for $2 \mathrm{~min}$ were used. The PCR product of $500 \mathrm{bp}$ long was recovered by Gene clean kit (BIO101) after 2\% agarose gel electrophoresis. For the second PCR, the first PCR product and $2 \mu \mathrm{g}$ of reverse primer (5'GTAAAACGACGGCCAGT3') were added together with $20 \mathrm{ng}$ of template (pADH5C) to PCR cocktail of $100 \mu$ final volume. The PCR profile was same as the first PCR. The $700 \mathrm{bp}$ amplicon was recovered and was double digested with SacI and PstI (New England Biolabs). The digested PCR product was ligated to the large fragment of SacI and Pst I digested pADH5C and generated the $\mathrm{pADH} 4 \mathrm{C}$ plasmid. The sequence of the insert in $\mathrm{pADH} 4 \mathrm{C}$ was confirmed by sequencing. These plasmids were engineered to express the recombinant proteins in bacteria and the parent vector of pADH5C was pUC19. Plasmid pADH5C has origin of replication derived from $\mathrm{pUC19}$, and Shine-Dalgarno sequence and $r n n \mathrm{~B}$ termination signal were derived from pKK233-2. The adh promoter was generated by gene synthesis. The gcGH cDNA was cloned in our laboratory as described previously (Ho et al., 1989).

Expression and renaturation of 4-Cys and 5-Cys rgcGH. To express the 4-Cys and 5-Cys $\mathrm{rgcGH}, \mathrm{pADH} 4 \mathrm{C}$ and pADH5C plasmids were transformed into E. coli bacterial strain JM109. Transformed bacteria were inoculated into $300 \mathrm{ml}$ of LB with 50 $\mathrm{mg} / \mathrm{ml}$ ampicillin and were grown at $30^{\circ} \mathrm{C}$ with shaking for $16 \mathrm{~h}$. LB with ampicillin was then added to the overnight culture to 2.7 liter. The culture was then incubated at $37^{\circ} \mathrm{C}$ to induce $\mathrm{rgcGH}$ expression for $6 \mathrm{~h}$. Cultured bacteria were harvested by centrifugation at $8,000 \mathrm{~g}$ at $4^{\circ} \mathrm{C}$ for $20 \mathrm{~min}$. Ice-cold suspension buffer $(50 \mathrm{mM}$ Tris-HCl, $2 \mathrm{mM}$ EDTA, $1.5 \mathrm{M} \mathrm{NaCl}, 1 \mathrm{mM}$ Phenylmethylsulphonylfluoride (PMSF), $\mathrm{pH}$ 8.5) of $10 \mathrm{ml}$ was added per gram of bacterial pellet. The bacterial cells were disintegrated by bead beater (Biospec Products Inc.) using $0.1 \mathrm{~mm}$ glass bead. The volume ratio of glass beads to bacterial suspension was $2: 1$. The bacteria were blended for $3 \mathrm{~min}$. Bacterial lysate was obtained by decanting and lysate was centrifuged at $12,000 \mathrm{rpm}$ at $4^{\circ} \mathrm{C}$ for 30 min. Supernatant was discarded and pellet was resuspended in wash buffer 1 (10 mM Tris-HCl, 0.01\% Triton X-100, 1 mM PMSF, pH 8.5 ) by stirring overnight at $4^{\circ} \mathrm{C}$. Inclusion bodies of rgcGH were collected by centrifugation $\left(12,000 \mathrm{rpm}, 4^{\circ} \mathrm{C}, 30 \mathrm{~min}\right)$. The inclusion bodies were washed with wash buffer $2(100 \mathrm{mM}$ Tris-HCl, $1 \mathrm{M}$ $\mathrm{GdnHCl}, \mathrm{pH} 8.5$ ) by stirring overnight at $4^{\circ} \mathrm{C}$. Washed inclusion bodies were centrifuged $\left(12,000 \mathrm{rpm}, 4^{\circ} \mathrm{C}, 30 \mathrm{~min}\right)$ and pellet was dissolved in renaturation buffer $1(6 \mathrm{M} \mathrm{GdnHCl}, 100 \mathrm{mM}$ Tris- $\mathrm{HCl}$, $2 \mathrm{mM}$ EDTA, $2 \mathrm{mM}$ reduced glutathione (GSH), $\mathrm{pH}$ 8.5) by stirring overnight at $4{ }^{\circ} \mathrm{C}$. Wash buffer and renaturation buffers of 10 $\mathrm{ml}$ was added per gram of bacterial pellet. Insoluble materials were removed by centrifugation $\left(12,000 \mathrm{rpm}, 4^{\circ} \mathrm{C}, 30 \mathrm{~min}\right)$. Renaturation buffer $2(10 \mathrm{mM}, 2 \mathrm{mM}$ EDTA, $4 \mathrm{mM}$ GSH, $0.4 \mathrm{mM}$ oxidized glutathione (GSSG), $\mathrm{pH} 8.5$ ) was added slowly to the supernatant at a rate of $1 \mathrm{ml} / \mathrm{min}$ with stirring at $4^{\circ} \mathrm{C}$ for $48 \mathrm{~h}$. The protein concentration of the diluted refolding mixture was estimated by Bradford protein reagent (Bio-Rad Labs) and was adjusted to below $1 \mathrm{mg} / \mathrm{ml}$ with renaturation buffer $3(3 \mathrm{M} \mathrm{Gdn}-\mathrm{HCl}, 10 \mathrm{mM}$ Tris$\mathrm{HCl}, 2 \mathrm{mM}$ EDTA, $4 \mathrm{mM}$ GSH, $0.4 \mathrm{mM}$ GSSG, $\mathrm{pH}$ 8.5). Two volumes of renaturation buffer 4 (10 mM Tris- $\mathrm{HCl}, 2 \mathrm{mM}$ EDTA, 4 mM GSH, 0.4 mM GSSG, $p H$ 8.5) were then added slowly at a rate of $1 \mathrm{ml} / 10 \mathrm{~min}$. The final protein solution has a volume of about 90 $\mathrm{ml}$. Denaturant in the protein solution was removed by stepwise 
dialysis. The protein solution was first dialyzed against 1 liter of dialysis buffer $(5 \mathrm{mM}$ Tris- $\mathrm{HCl}, 1 \mathrm{mM}$ EDTA, $\mathrm{pH} 8.0)$ at $4^{\circ} \mathrm{C}$ for $4 \mathrm{~h}$. The protein solution was further dialyzed for 3 times at $4^{\circ} \mathrm{C}$ for $12 \mathrm{~h}$ each.

Gel filtration chromatography of 4-Cys and 5-Cys rgcGH. Freshly in vitro refolded bacterial expressed 4-Cys and 5-Cys rgcGH of $0.5 \mathrm{ml}$ was loaded onto a superose 12 column (Amersham Biosciences). The chromatography was run by a Fast Protein Liquid Chromatography (FPLC) system (Amersham Biosciences). The mobile phase was $0.02 \mathrm{M}$ sodium phosphate, $\mathrm{pH} 7.4$ and the flow rate was maintained at $1 \mathrm{ml} / \mathrm{min}$. Protein elution was monitored by the measurement of OD 260. Eluted peaks and fraction were collected for SDS-PAGE and Western Blot analysis.

Reverse phase (RP)-FPLC of monomeric 4-Cys and 5-Cys rgcGH. Peak 2 of 4-Cys and 5-Cys rgcGH from gel filtration chromatography were adjusted to $400 \mathrm{mg} / \mathrm{ml}$ and were loaded onto a C-18 reverse phase column (Amersham Biosciences). The mobile phase was distilled water and acetonitrile (ACN) with $0.1 \%$ trifluoroacetic acid. The flow rate was maintained at $1 \mathrm{ml} / \mathrm{min}$. The ACN concentration of mobile phase was increased from $0 \%$ to $30 \%$ at $15 \mathrm{~min}$ after sample loading and the $30 \% \mathrm{ACN}$ was maintained for $15 \mathrm{~min}$. The ACN \% was then increased linearly to $100 \%$ in 30 min. Protein elution was monitored by the measurement of OD 260. Eluted peaks were collected for SDS-PAGE and Western Blot analysis. Native grass carp growth hormone (ngcGH), which was purified from mature grass carp pituitaries by immuno-affinity chromatography (unpublished data), was used for comparison.

Western blot. Proteins were first resolved by SDS-PAGE (Laemmli 1970) and were then electro-transferred from gel to nitrocellulose membrane (Bio-Rad Labs) by electroblotter (Bio-Rad Labs). The procedures followed that of Towbin et al... (Towbin et al., 1979). The membrane was then pre-blocked with PBS with $0.05 \%$ Tween 20 and 5\% skim milk (PBSTM) at room temperature for $1 \mathrm{~h}$ with shaking. The pre-blocked membrane was transferred to PBSTM with $0.5 \mu \mathrm{g} / \mathrm{ml}$ of anti-gcGH monoclonal antibody at $4^{\circ} \mathrm{C}$ overnight. The antibody was prepared in our laboratory by fusing NS-1 myeloma cell line with splenic lymphocytes from ngcGH hyperimmunized mice (unpublished data). The incubated membrane was washed three times with PBST and was then incubated with 2,000:1 goat antimouse IgG alkaline phosphatase conjugate (Bio-Rad Labs) in PBSTM at room temperature for $2 \mathrm{~h}$. The membrane was washed five times with PBST. Chromophore was developed by adding NBT/ BCIP in barbital acetate buffer of $0.15 \mathrm{M}, \mathrm{pH} 9.6$ at room temperature.

Receptor binding assay. Goldfish liver membrane was prepared according to Tsushima et al., (1973) with slight modifications. Livers, collected from 30 fishes, were rinsed in $0.3 \mathrm{M}$ sucrose, blotted dry, and were weighted. The liver tissue was minced and homogenized in 4 volumes of $0.3 \mathrm{M}$ sucrose solution. The homogenate was centrifuged at $10,000 \mathrm{~g}$ for $10 \mathrm{~min}$. Supernatant was further centrifuged at $105,000 \mathrm{~g}$ for $60 \mathrm{~min}$. The pellet was resuspended in $24 \mathrm{mM}$ Tris- $\mathrm{HCl}$ buffer $(\mathrm{pH}$ 7.2). The protein concentration of the membrane preparation was determined by Bradford reagent (Bio-Rad Labs). Recombinant seabream growth hormone (rsbGH) was iodinated by lactoperoxidase (Calbiochem) method (Thorell et al., 1971). Both rsbGH and lactoperoxidase of 5 $\mu \mathrm{g}$ were dissolved in $30 \mu \mathrm{l}$ of $0.4 \mathrm{M}$ sodium acetate ( $\mathrm{pH}$ 5.6). The hormone-enzyme cocktail was then mixed with $1 \mathrm{mCi}$ of $\mathrm{Na}^{125} \mathrm{I}$ (Amersham Biosciences). Iodination was initiated by adding $10 \mu \mathrm{l}$ of $\mathrm{H}_{2} \mathrm{O}_{2}$. The reaction was proceeded at room temperature for $1 \mathrm{~min}$ and then terminated by the addition of $100 \mu$ of transfer buffer $(0.01 \mathrm{M}$ sodium phosphate, $1 \%$ potassium iodide, $16 \%$ sucrose, $0.1 \%$ sodium azide, $\mathrm{pH} 7.5$ ) and $50 \mu$ l of $5 \%$ BSA. Iodinated GH was separated from free ${ }^{125} \mathrm{I}$ by PD-10 desalting column (Amersham Biosciences). Radioreceptor binding procedures followed the method of Shiu et al., (1974) with slight modifications. Membrane preparation of $1 \mathrm{mg}$ protein in $100 \mu \mathrm{l}$ assay buffer $(20 \mathrm{mM} \mathrm{CaCl}$, $25 \mathrm{mM}$ Tris- $\mathrm{HCl}, 0.4 \%$ BSA, $\mathrm{pH}$ 7.2) was equilibrated with $100,000 \mathrm{cpm}{ }^{125} \mathrm{I}-\mathrm{rsbGH}(100 \mu \mathrm{l})$, and various concentrations of 4Cys $\mathrm{rgcGH}$, 5-Cys $\mathrm{rgcGH}$, ngcGH and rsbGH. The reaction cocktail, had a final volume of $500 \mu \mathrm{l}$, was equilibrated at $4^{\circ} \mathrm{C}$ for $24 \mathrm{~h}$. Hormone-receptor complex was pelleted by centrifugation at $5,000 \mathrm{~g}$ at $4{ }^{\circ} \mathrm{C}$ for $60 \mathrm{~min}$. The radioactivity of the collected pellet was determined by Gamma counter (Beckman Coulter).

Statistical analysis. Student's $t$-test was used to determine significant difference at $p<0.05$.

\section{Results}

Expression of 4-Cys and 5-Cys rgcGH. 4-Cys rgcGH mutant cDNA generated by double PCR method was confirmed by sequencing. Both wild type (5-Cys) rgcGH and mutant (4-Cys) rgcGH were expressed in E. coli and were renatured in vitro. SDS-PAGE revealed the levels of inclusion bodies in 4-Cys and 5-Cys transformed E. coli are comparable (Fig. 1A). Both E. coli expressed 4-Cys and 5-Cys rgcGH had characteristic molecular weight of $22 \mathrm{kDa}$. The refolded 4Cys and 5-Cys rgcGH were immunologically indistinguishable when detected by Western blot (Fig. 1B). The yields of 4-Cys and 5-Cys rgcGH when calculated from three separate refolding batches were $268 \pm 29 \mathrm{mg} / \mathrm{L}$ and $300 \pm 37 \mathrm{mg} / \mathrm{L}$ bacterial culture. The means are comparable and the difference is not significant.

Gel filtration chromatography of 4-Cys and 5-Cys rgcGH. To monitor the degree of self-association of refolded $\mathrm{rgcGH}$, freshly refolded 4-Cys and 5-Cys rgcGH were analyzed by gel filtration chromatography. The chromatograms of 4-Cys and 5-Cys rgcGH are similar, the two major peaks; peak 1, peak 2, and also fraction eluted in between the peaks were collected for SDS-PAGE (Fig. 2A and 2B). Peak 1 eluted at void volume must be multimeric $\mathrm{rgcGH}$ as the protein exclusion limit of the column was $2,000 \mathrm{kDa}$, and the fraction collected in between peak 1 and peak 2 represented oligomeric rgcGH. Peak 2 with elution of about $22 \mathrm{kDa}$ was the monomeric rgcGH. The mean ratios of multimers and oligomers to monomer determined from chromatograms of three different batches of refolding mixture were $0.83 \pm 0.11$ and $1.34 \pm 0.17$ for 4-Cys rgcGH and 5-Cys rgcGH respectively. The difference is significant. A higher ratio suggested more aggregates. 


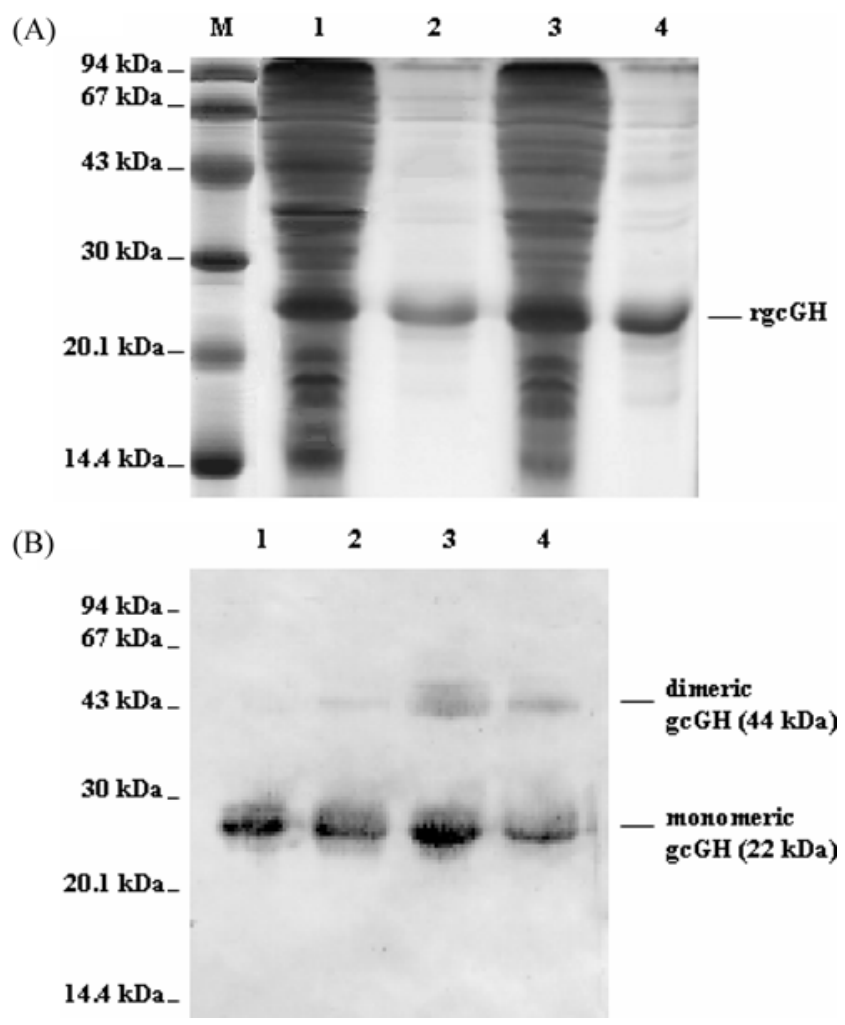

Fig. 1. Expression of 4-Cys $\mathrm{rgcGH}$ and 5-Cys rgcGH. SDSPAGE (Fig. 1A) and Western blot (Fig.1B) of in vitro refolded 4-Cys and 5-Cys rgcGH. Marker (M), lysate of bacteria that expressed 4-Cys rgcGH (lane 1), 4-Cys rgcGH inclusion bodies (lane 2), lysate of bacteria that expressed 5-Cys rgcGH (lane 3), 5-Cys rgcGH inclusion bodies (lane 4). The major band which had molecular weight (MW) of $22 \mathrm{kDa}$ was the monomeric $\mathrm{rgcGH}$ and the minor band which had MW of around $44 \mathrm{kDa}$ was the dimeric $\mathrm{rgcGH}$.

RP-FPLC of 4-Cys and 5-Cys rgeGH. Immunoaffinity purified ngcGH was used as standard for RP-FPLC of 4-Cys and 5-Cys rgcGH. The major peak of RP-FPLC of affinitycolumn purified ngcGH represented the monomeric ngcGH molecule with native topology (Fig. 3A), and the present of isoforms would be resolved as separate peaks. The major peak of ngcGH was eluted at $51.5 \%$ of acetonitrile $(\mathrm{ACN})$. In vitro refolded $\mathrm{rgcGH}$, which had topology identical to that of ngcGH should have the same retention. The chromatogram of 4-Cys rgcGH demonstrated the refolded $\mathrm{rgcGH}$ was eluted as one major peak at $51.5 \%$ of ACN (Fig. 3B). However, the chromatogram of 5-Cys rgcGH showed three major peaks of very close retention (Fig. 3C). The three peaks were eluted from $50 \%-51.5 \%$ of $\mathrm{ACN}$. The one eluted at $51.5 \%$ should have native topology and the other two must be isoforms.

Radio-receptor binding assay. The receptor binding properties of the refolded rgcGHs were compared with that of ngcGH by radio-receptor binding assay. Goldfish liver membrane, which was rich in GH receptor, was prepared for the assay. The
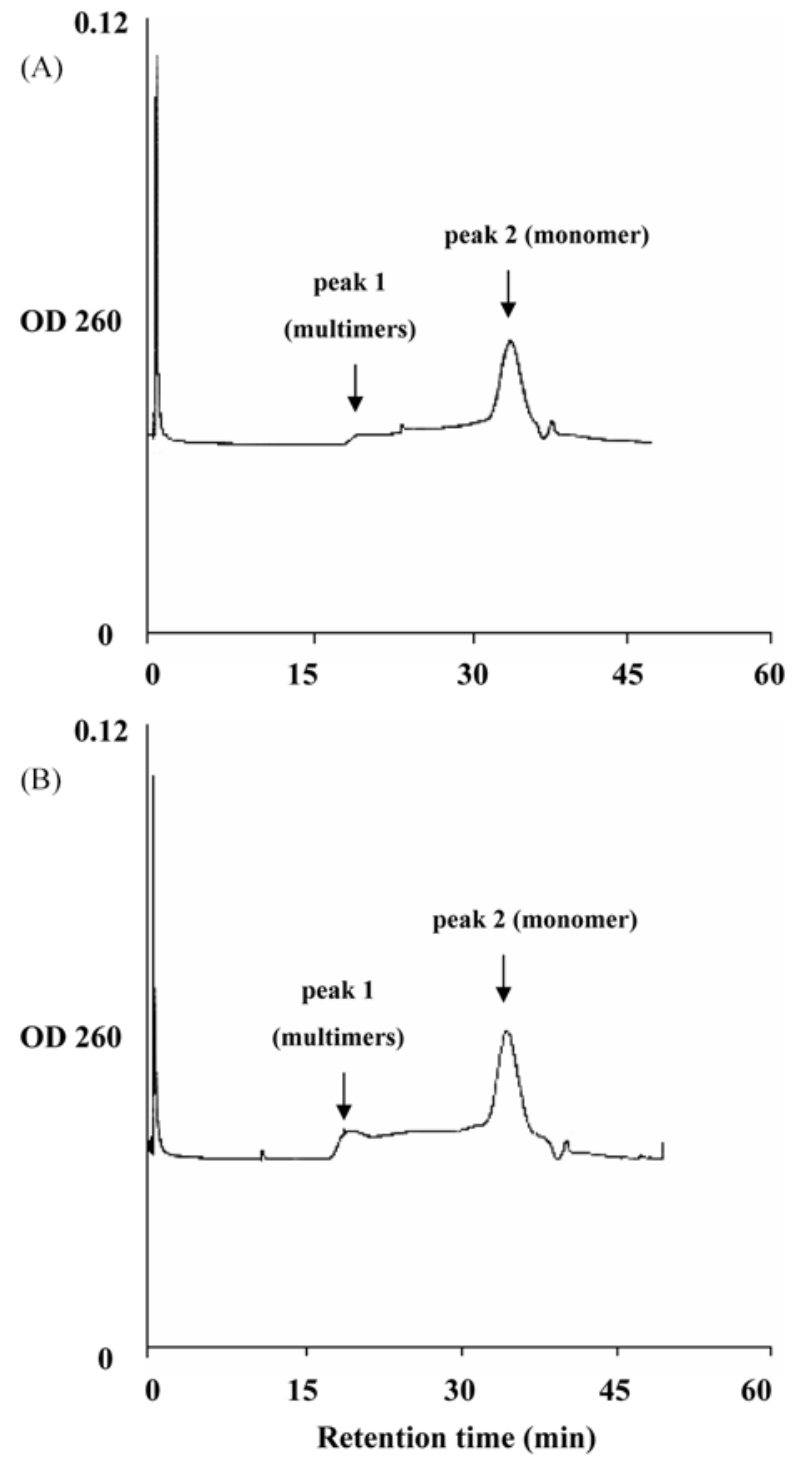

Fig. 2. Representative gel filtration chromatograms of in vitro refolded 4-Cys and 5-Cys rgcGH of three individual expression and refolding mixtures. Refolded protein solution of $0.5 \mathrm{ml}$ was loaded onto a superose 12 column. The elution profile of 4-Cys rgcGH $(2 \mathrm{~A})$ and 5-Cys rgcGH (2B) were similar. Peak 1, which was eluted at void volume, contained multimeric $\mathrm{rgcGH}$. Fraction eluted in between peak 1 and peak 2 represented oligomeric $\operatorname{rgcGH}$. Peak 2 was the monomeric $\operatorname{rgcGH}$. The mean values of multimeric and oligomeric $\mathrm{rgcGH}$ to monomeric $\mathrm{rgcGH}$ for 4-Cys and 5-Cys forms when calculated from three separate refolding batches were $0.83 \pm 0.11$ and $1.34 \pm 0.17$.

displacement curves of the refolded $\mathrm{rgcGHs}$ and ngcGH were shown in Fig. 4. All the GH tested displaced receptor bound ${ }^{125} \mathrm{I} \mathrm{rsbGH}$ in a dose dependent manner. The mean $\mathrm{EC}_{50}$ values of 4-Cys and 5-Cys forms calculated from three binding experiments using three separate batches of refolded 4-Cys and 5-Cys rgcGH were $2.3 \pm 1.2,4.6 \pm 1.8,7.0 \pm 2.1$ and 7.9 \pm 1.9 for rsbGH, 5-Cys $\mathrm{rgcGH}$, ngcGH and 4-Cys $\mathrm{rgcGH}$ 

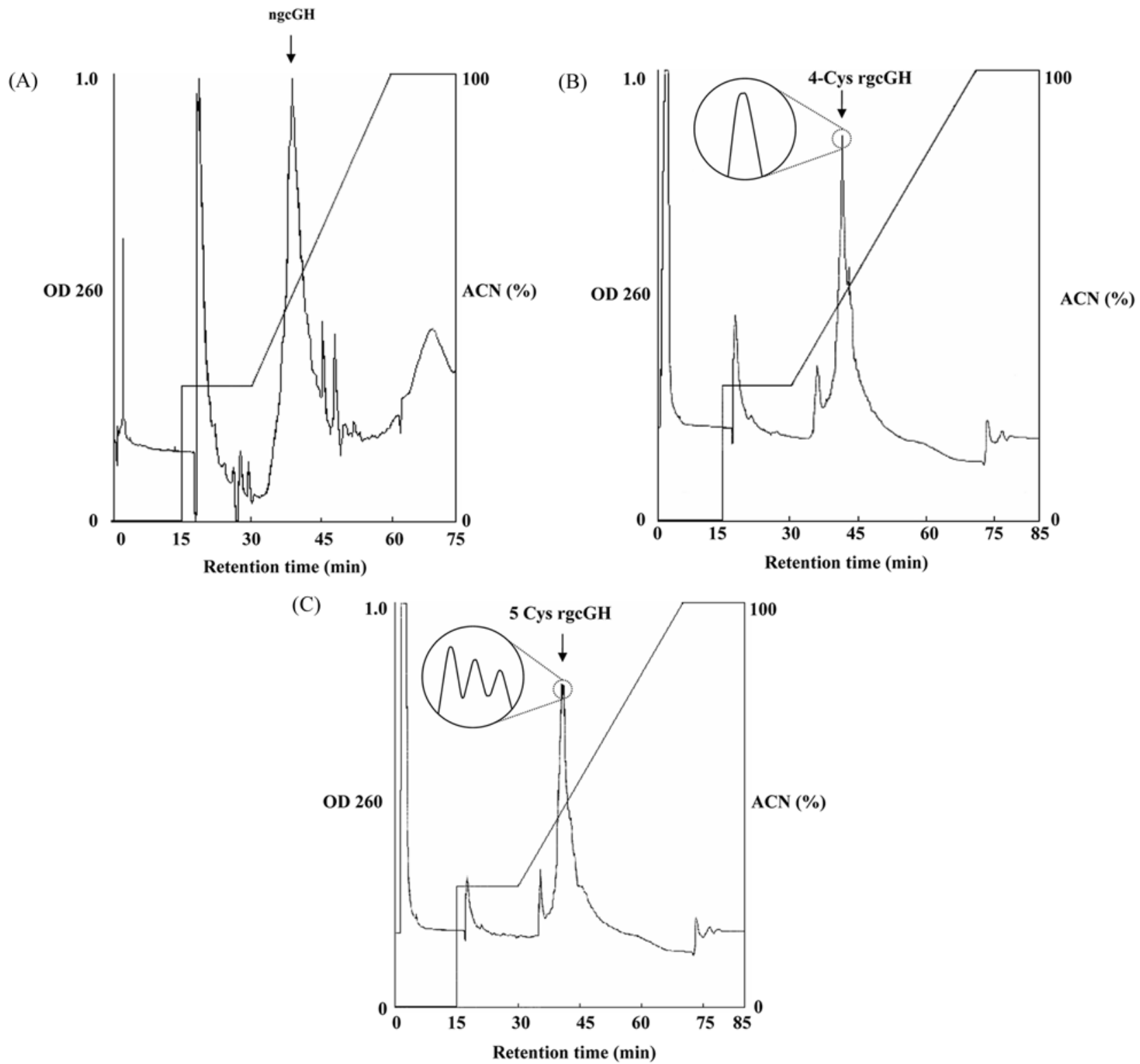

Fig. 3. Representative reverse phase chromatograms of ngcGH (3A), and monomeric 4-Cys rgcGH (3B) and monomeric 5-Cys rgcGH (4C). Monomeric 4-Cys and 5-Cys rgcGH were derived from gel filtration chromatography. Monomeric $\mathrm{rgcGH}$ of $200 \mu \mathrm{lat} 400 \mu \mathrm{g} / \mathrm{ml}$ was loaded onto a reverse phase C-18 column. The straight lines represent acetonitrile (ACN) gradient. Both native and 4-Cys rgcGH, had a single major peak, were eluted at 51.5\% of ACN. 5-Cys rgcGH, had 3 major peaks, were eluted from 50-51.5\% of ACN. Inset is an enlargement of the eluted peak(s).

respectively. Though 5-Cys $\mathrm{rgcGH}$ has lower $\mathrm{EC}_{50}$ than $\mathrm{ngcGH}$ and 4-Cys rgcGH, the difference is not significant.

\section{Discussion}

Although prokaryotic expression system usually expresses heterologous protein as inclusion bodies, it is still our choice for the expression of rgcGH as the growth of bacteria and the delivery of DNA into bacteria is simple and economical. Also, the expression level of recombinant protein in bacteria excels other expression systems, as the recombinant protein level can be as high as $30 \%$ of the total cell protein (Li et al., 2004). In our study, the expression level was about $10 \%$ of the total bacterial cell protein. Serine was selected for the substitution of the non-disulphide-bond-forming Cys in order to minimize change in steric and hydrophobic properties of the amino acid side chain. This minimized the undesirable effect of the mutation on the protein folding.

We attempted to use Western blot/immunological method, gel filtration chromatography and reverse phase chromatography to study the heterogeneity of in vitro refolded $\mathrm{rgcGH}$. Our 


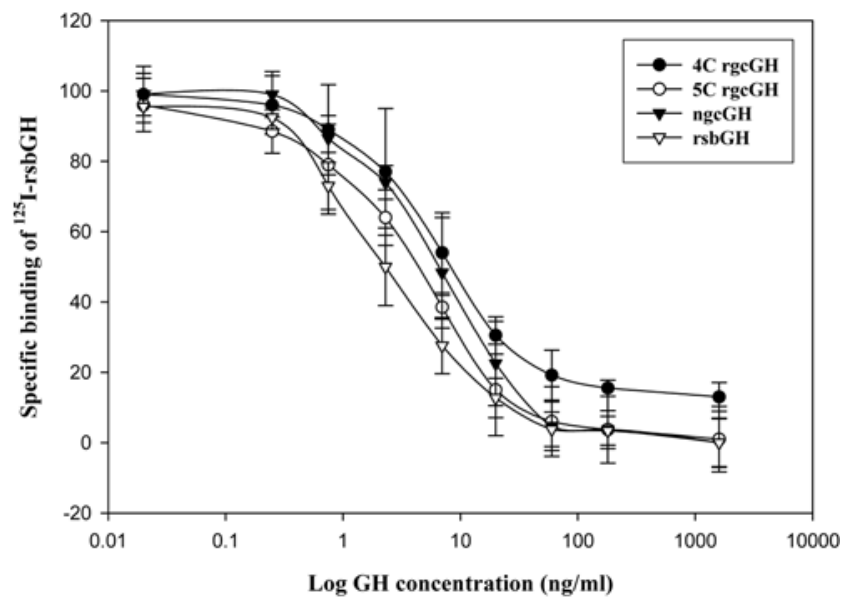

Fig. 4. Displacement of goldfish liver membrane bound ${ }^{125} \mathrm{I}$ rsbGH by 4-Cys $\mathrm{rgcGH}$, 5-Cys $\mathrm{rgcGH}$, ngcGH and rsbGH. Goldfish liver membrane preparation was saturated with ${ }^{125} \mathrm{I}$ labeled rsbGH. The ${ }^{125} \mathrm{I}$ rsbGH bound membrane preparation was equilibrated with various concentrations of 4-Cys $\mathrm{rgcGH}$, 5-Cys rgcGH, ngcGH and rsbGH. Hormone-receptor complex was washed and was pelleted. Radioactivity, of the membrane pellet, was counted by gamma counter. The refolded 4-Cys rgcGH, 5Cys rgcGH and ngcGH displaced membrane bound ${ }^{125} \mathrm{I}$ rsbGH in a dose dependent manner. Each point is mean $\pm \mathrm{SD}$ of triplicate determinations. The mean $\mathrm{EC}_{50}$ values of $\mathrm{rsbGH}$, 5-Cys rgcGH, ngcGH and 4-Cys rgcGH are $2.3 \pm 1.2,4.6 \pm 1.8,7.0 \pm 2.1$ and $7.9 \pm 1.9$. Though 5 -Cys rgcGH has lower $\mathrm{EC}_{50}$ than $\mathrm{ngcGH}$ and 4-Cys $\mathrm{rgcGH}$, the difference is not significant.

results demonstrated immunological method was not feasible for that purpose. To study the structural heterogeneity of the refolded protein, the global topological difference of $\mathrm{rgcGH}$ molecules in the refolded protein cocktail must be distinguished. Antibody only recognizes a short amino acid motif or epitope of a protein is thus only suitable for local topological study rather than global topological study. Both gel filtration and reverse phase chromatography were useful in the study of in vitro refolded $\mathrm{rgcGH}$. Gel filtration, which successfully distinguished monomeric rgcGH from oligomeric and multimeric $\mathrm{rgcGH}$, were used to measure the ratio of aggregated $\mathrm{rgcGH}$ to monomeric rgcGH. However, gel filtration was unable to distinguish monomeric rgcGH isoforms and was supplemented by RP chromatography, which resolved the monomeric isoforms of refolded $\mathrm{rgcGH}$.

RP chromatography suggested the monomeric fraction of 4-Cys refolded rgcGH had only one isoform which had structure similar to that of ngcGH as both gcGHs had identical retention time. In ngcGH, Cys 49 bonds with Cys 161 to form a major loop and Cys 178 bonds with Cys 186 to form a minor loop. Presumably, the three major peaks observed in 5Cys rgcGH represented 3 isoforms of different disulphide bonds. For the random joining of the Cys residues to form 2 disulphide bonds, the presence of 5-Cys residues in wide type $\mathrm{rgcGH}$ can potentially generate 12 isoforms of different disulphide bridges. In case of 4-Cys $\mathrm{rgcGH}$, the potential disulphide bridges isoforms are reduced to 3 only. The mutation thus greatly reduced the probability of improper disulphide bonds formation during oxidative in vitro refolding process. The presence of only one isoform in the monomeric fraction of 4-Cys $\mathrm{rgcGH}$, the native form, suggested the formation of disulphide bonds between Cys 49 or Cys 161 with Cys 178 or Cys 186 was energetically not favorable. Based on this notion, the non-disulphide-bond-forming Cys (Cys 123) probably only formed disulphide-bonds with Cys 49 or Cys 161. This explains the three major peaks observed in the monomeric fraction of 5-Cys rgcGH.

We also demonstrated the refolded rgcGHs have active conformations by receptor binding assay. The similar displacement potency of the refolded $\mathrm{rgcGH}$ and ngcGH indicates that the in vitro oxidative renatured 4-Cys and 5-Cys $\mathrm{rgcGH}$, and ngcGH have similar receptor binding affinity. Since hormone action is initiated by the binding of hormone molecule to receptor and then triggers subsequent cellular event. The binding of the hormone to goldfish $\mathrm{GH}$ receptor suggested that the refolded 4-Cys and 5-Cys rgcGH have biologically active conformations. However, the data cannot be interpreted as a direct projection of the hormones bioactivity for two reasons. Pearce et al.,. (Pearce et al., 1999) generated various high and low receptor affinity $\mathrm{GH}$ variants. The high affinity mutants did not increase $\mathrm{EC}_{50}$ for cell proliferation or the levels of JAK2 tyrosine kinase phosphorylation in in vitro bioassay, and $\mathrm{EC}_{50}$ for cell proliferation was only affected when the affinity was reduced by 30 folds. Another reason is there exist a lot of growth hormone variants and aggregates (22 kDa form, $20 \mathrm{kDa}$ form, acetylated form, phosphorylated form, glycosylated form, deamidated form, fragments, dimers, trimers, tetramers, pentamers and oligomers) in plasma (Baumann G. 1999; De Palo et al., 2005). Fragments of GH are derived from intact $\mathrm{GH}$ molecules by proteolytic cleavage, and some of the fragments are biologically active. The actual potency and function of most of these variants and aggregates are still obscure. The function and potency of such variants and aggregates in vivo were determined by their clearance rate, pattern of fragmentation, binding to high affinity or low affinity growth hormone binding proteins (GHBPs) in plasma, and the effect on GH regulatory axis. Therefore, how the 4Cys form and 5-Cys form of bacterial refolded rgcGH are cleared, fragmented, interact with GHBPs, affect the GH regulatory axis in vivo require further elucidation. In terms of yield, 4-Cys form has no advantage over the 5-Cys form when refolded by our experimental protocol. However, 4-Cys form has more monomeric GH over oligomeric GH than 5-Cys form in the refolding mixtures. Arosio et al.,. (Arosio et al., 1991) found that oligomeric GH mediated lower level of IGFI in vivo and suggested oligomeric $\mathrm{GH}$ had lower bioactivity. Conceivably, 4-Cys rgcGH refolding mixture may have higher biological activity than 5-Cys form in vivo.

The presence of odd number of cysteine residues in protein is common in GHs of the Cyprinidae family (Chang et al., 
1992) but not other proteins. The in vivo biological significant of having odd number/five Cys in fish GHs is still not clear.

In conclusion, in vitro refolded monomeric rgcGH was purified from refolding mixture by gel filtration chromatography. Gel filtration chromatography together with reverse-phase chromatography distinguished the heterogeneity of the refolded 4-Cys and 5-Cys rgcGH mixtures. The conversion of non-disulphide-bond-forming Cys in gcGH improved the in vitro oxidative renaturation properties of bacterial expressed rgcGH. The refolded 4-Cys and 5-Cys rgcGH were active in terms of receptor binding.

Acknowledgments This project was partially funded by Earmarked grant from Research Grant Council of Hong Kong SAR government.

\section{References}

Arosio, M., Nissim, M., Ballabio, M., Orefice, R., Bazzoni, N. and Faglia, G. (1991) Size heterogeneity of circulating growth hormone in acromegaly. "Big-big" GH forms are associated with inappropriately low IGF-I levels. Acta Endocrinol. (Copenh). 125, 150-159.

Baumann, G. (1999) Growth hormone heterogeneity in human pituitary and plasma. Horm Res. 51, 2-6.

Bhuyan, A. K. and Udgaonkar, J. B. (2001) Folding of Horse Cytochrome $\mathrm{c}$ in the Reduced State. J. Mol. Biol. 312, 11351160.

Bulled, N. J. and Freedman, R. B. (1988) Defective cotranslational formation of disulphide bonds in protein disulphide-isomerase-deficient microsomes. Nature 335, 649651.

Chang, Y. S., Liu, C. S., Huang, F. L. and Lo, T. B. (1992) The primary structures of growth hormones of three cyprinid species: bighead carp, silver carp, and grass carp. Gen Comp Endocrinol. 87, 385-393.

Creighton, T. E., Hillson, D. A. and Freedman, R. B. (1980) Catalysis by protein-disulphide isomerase of the unfolding and refolding of proteins with disulphide bonds. J. Mol. Biol. 142, 43-62.

De Bernande, C. E., Schwarz E. and Rudolph, R. (1999) Inhibition of aggregation side reactions during in vitro protein folding. Methods Enzymol. 309, 217-236.

De Palo, E. F., De Filippis, V., Gatti, R. and Spinella, P. (2005) Growth hormone isoforms and segments/fragments: Molecular structure and laboratory measurement. Clin. Chim. Acta 26, Epub ahead of print.

Dolgikh, D. A., Abaturov, L. V., Bolotina, I. A., Brazhnikov, E. V., Bychkova, V. E., Gilmanshin, R. I., Lebedev, Y. O., Semisotnov, G. V., Tiktopulo, E. I. and Ptitsyn, O. B. (1985) Compact state of a protein molecule with pronounced smallscale mobility: bovine alpha-lactalbumin. Eur. Biophys. J. 13, 109-121.

Dolgikh, D. A., Gilmanshin, R. I., Brazhnikov, E. V., Bychkova, V. E., Semisotnov, G. V., Venyaminov, S. Y. and Ptitsyn, O. B. (1981) Alpha-Lactalbumin: compact state with fluctuating tertiary structure? FEBS Lett. 136, 311-315.
Dolgikh, D. A., Kolomiets, A. P., Bolotina, I. A. and Ptitsyn, O. B. (1984) 'Molten-globule' state accumulates in carbonic anhydrase folding. FEBS Lett. 165, 88-92.

Eaton, W. A., Muñoz, V., Thompson, P. A., Chan, C. K. and Hofrichter, J. (1997) Submillisecond kinetics of protein folding. Curr. Opinion Struct. Biol. 7, 10-14.

Frand, A. R. and Kaiser, C. A. (1998) The EROI gene of yeast is required for oxidation of protein dithiols in the endoplasmic reticulum. Mol. Cell. 1, 161-170.

Frand, A. R., Cuozzo, J. and Kaiser, C. A. (2000) Pathways for proteins disulphide bond formation in the endoplasmic reticulum. Trends Cell Biol. 5, 203-210.

Futami, J., Tsushima, Y., Tada, H., Seno, M. and Yamada, H. (2000) Convenient and efficient in vitro folding of disulphidecontaining globular protein from crude bacterial inclusion bodies. J. Biochem. (Tokyo) 127, 435-441.

Gorovits, B. M. and Horowitz, P. M. (1998) High hydrostatic pressure can reverse aggregation of protein folding intermediates and facilitate acquisition of native structure. Biochemistry 37, 6132-6135.

Hartl, F. U. (1996) Molecular chaperones in cellular protein folding. Nature 381, 571-580.

Hartley, D. L. and Kane, J. F. (1988) Properties of inclusion bodies from recombinant Escherichia coli. Biochem. Soc. Trans. 16, 101-102.

Ho, W. K., Tsang, W. H. and Dias, N. P. (1989) Cloning of the grass carp growth hormone cDNA. Biochem. Biophys. Res. Commun. 161, 1239-43.

Huth, J. R., Norton, S. E., Lockridge, O., Shikone, T., Hsueh, A. J. and Ruddon, R. W. (1994) Bacterial expression and in vitro folding of the beta-subunit of human chorionic gonadotropin (hCG beta) and functional assembly of recombinant hCG beta with hCG alpha. Endocrinology 135, 911-918.

Jakob, U. and Buchner, J. (1994) Assisting spontaneity: the role of Hsp90 and small Hsps as molecular chaperones. Trends Biochem. Sci. 19, 205-211.

Jonda, S., Huber-Wunderlich, M., Glockshuber, R. and Mössner, E. (1999), Complementation of DsbA deficiency with secreted thioredoxin variants reveals the crucial role of an efficient dithiol oxidant for catalyzed protein folding in the bacterial periplasm. EMBO J. 18, 3271-3281.

Laemmli, U. K. (1970) Cleavage of structural proteins during the assembly of the head of bacteriophage T4. Nature 227, 680685.

Li, M., Su, Z. G. and Janson, J. C. (2004) In vitro protein refolding by chromatographic procedures. Protein Expr. Purif. 33, 1-10.

Lilie, H., Schwarz, E. and Rudolph, R. (1998) Advances in refolding of proteins produced in E. coli. Curr. Opin. Biotechnol. 9, 497-501.

Misawa, S. and Kumagai, I. (1999) Refolding of therapeutic proteins produced in Escherichia coli as inclusion bodies. Biopolymers (Peptide Science) 51, 297-307.

Nath, D. and Rao, M. (2001) Artificial chaperone mediated refolding of xylanase from an alkalophilic thermophilic Bacillus sp. Implications for in vitro protein renaturation via a folding intermediate. Eur. J. Biochem. 268, 5471-5478.

Ohgushi, M. and Wada, A. (1983) 'Molten-globule state': a compact form of globular proteins with mobile side-chains. FEBS Lett. 164, 21-24. 
Pearce, K. H. Jr., Cunningham, B. C., Fuh, G., Teeri, T. and Wells, J. A. (1999) Growth hormone binding affinity for its receptor surpasses the requirements for cellular activity. Biochemistry 38, 81-89.

Puri, N. K., Crivelli, E., Cardamone, M., Fiddes, R., Bertolini, J., Ninham, B. and Brandon, M. R. (1992) Solubilization of growth hormone and other recombinant proteins from Escherichia coli inclusion bodies by using a cationic surfactant. Biochem. J. 285, 871-879.

Rudolph, R. and Lilie, H. (1996) In vitro folding of inclusion body proteins. FASEB J. 10, 49-56.

Shiu, R. P. C. and Friesen, H. G. (1974) Properties of a prolactin receptor from the rabbit mammary gland. Biochem. J. 140, 301-311.

Sosnick, T. R., Mayne, L. and Englander, S. W. (1996) Molecular collapse: the rate-limiting step in two-state cytochrome c folding. Proteins 24, 413-426.

Tayyab, S., Ahmad, B., Kumar, Y. and Khan, M. M. (2002) Saltinduced refolding in different domains of partially folded bovine serum albumin. Int. J. Biol. Macromol. 30, 17-22.

Thorell, J. I. and Johansson, B. G. (1971) Enzymatic iodination of polypeptides with ${ }^{125} \mathrm{I}$ to high specific activity. Biochem. Biophys. Acta 251, 363-369.

Towbin, H., Stachelin, T. and Gordon, J. (1979) Electrophoretic transfer of proteins from polyacrylamide gels to nitrocellulose sheets: Procedure and some applications. Proc. Natl. Acad. Sci. 76, 4350-4354.

Tsushima, T. and, Friesen, H. G. (1973) Radioreceptor assay for growth hormone. J. Clin. Endocrinol. Metab. 37, 334-337.

Weissman, J. S. and Kim, P. S. (1993) Efficient catalysis of disulphide bond rearrangements by protein disulphide isomerase. Nature 365, 185-188.

West, S. M., Chaudhuri, J. B. and Howell, J. A. (1998) Improved protein refolding using hollow-fibre membrane dialysis. Biotechnol. Bioeng. 57, 590-599.

Williams, D. C., Van Frank, R. M., Muth, W. L. and Burnett, J. P. (1982) Cytoplasmic inclusion bodies in Escherichia coli producing biosynthetic human insulin proteins. Science 215, 687-689.

Yin, G. and Swartz, J. R. (2004) Enhancing multiple disulphide bonded protein folding in a cell-free system. Biotechnol. Bioeng. 86, 188-195. 